\title{
ANÁLISE ECONÔMICA DO DIREITO COMO ELEMENTO CONCRETIZADOR DA TEORIA ESTRUTURANTE DO DIREITO
}

\author{
Maria Lírida Calou de Araújo e Mendonça ${ }^{1}$ \\ Arnaldo Coelho da Silva Filho ${ }^{2}$ \\ Vicente de Paulo Augusto de Oliveira Júnior ${ }^{3}$
}

\section{Resumo}

A presente pesquisa objetivou demonstrar a possibilidade de interseção entre a Teoria Estruturante do Direito e a Análise Econômica do Direito (AED). Realizada por intermédio de uma metodologia lógico-dedutiva pautada em revisão bibliográfica, de forma qualitativa, verificou-se que, desde a evolução doutrinária do movimento positivista ao pós-positivista, a utilização da Análise Econômica do Direito tornou-se ferramenta fundamental para a concretização da Teoria Estruturante do Direito, com, inclusive, complementação de suas características em torno de um Direito eficiente nos casos cujos recursos sejam escassos e limitados. Concluiu-se que a AED poderá ser aplicada como elemento dogmático do âmbito da norma da Teoria Estruturante do Direito, enquanto auxiliar que possibilita a concretização da melhor norma de decisão, especialmente pela possibilidade de previsão da análise normativa.

Palavras-chave: Norma; Teoria Estruturante do Direito; Análise Econômica do Direito; Melhor norma de decisão; Positivismo.

\section{INTRODUÇÃO}

O movimento denominado como pós-positivismo inovou a ciência jurídica contemporânea, por intermédio da exposição de lacunas e falhas em teorias estruturadas em uma dogmática tradicional, mas que permitiu a suscitação de uma série de questionamentos acerca da vertente reducionista de seu estudo.

Nesse contexto, torna-se imperativo uma análise apurada do Direito, que não se restringe à simples

\footnotetext{
${ }^{1}$ Pós-Doutora em Direito Tributário pela Universidade de Santa Catarina (UFSC). Professora titular do programa de pósgraduação strictu sensu - mestrado e doutorado - em Direito Constitucional e do curso de graduação em Direito da Universidade de Fortaleza (UNIFOR/CE). Coordenadora e professora do curso de graduação em Direito do Centro Universitário Católica de Quixadá (UNICATÓLICA). Coordenadora-chefe do Grupo de Estudos e Pesquisas em Direito Administrativo e Tributário (GEPDAT).E-mail: liridacalou@unifor.br

${ }^{2}$ Mestrando em Direito Constitucional Público e Teoria Política, pela Universidade de Fortaleza (UNIFOR/CE). Membro do Grupo de Estudos e Pesquisas em Direito Administrativo e Tributário (GEPDAT). E-mail: arnaldo.csf@gmail.com

${ }^{3}$ Doutorando em Direito Constitucional Público e Teoria Política, pela Universidade de Fortaleza (UNIFOR/CE). Coordenador do Grupo de Estudos e Pesquisas em Direito Administrativo e Tributário (GEPDAT).E-mail: vicenteaugusto2@gmail.com
} 
delimitação da estrutura normativa presente nos ordenamentos jurídicos, mas que se pauta por questões diversas, mas inter-relacionadas, tais como aquelas que expõem a funcionalização do Direito e suas raízes axiológicas; a que apresenta uma interpretação direcionada à fuga dos vícios de um estado de exceção hermenêutico, entre tantas outras.

Restaram evidenciadas as limitações da lei escrita frente à moral e seus valores, com especial foco em elementos anexos à norma, mas que a influenciam de forma intrínseca. Surgiu, como consequência imediata, um esforço para que se estabelecesse uma separação entre lei e norma - ou melhor, entre o texto escrito e a normatividade, bem como o reconhecimento da força normativa dos princípios. Essa medida tanto reforça a teoria jurídica, quanto implica em impactos na sua prática nos tribunais.

A revisão crítica do movimento que restou conhecido como positivismo legalista, foi impulsionada por várias teorias adjacentes, tais como a Teoria Estruturante do Direito, de Friedrich Müller. Apesar de ser caracterizada como uma corrente teórica que iria analisar a ciência jurídica além do positivismo legalista dominante, é crítica a uma teoria dos princípios e seu eventual sopesamento - que corresponde a uma das marcas do estudo dos pós-positivistas. Entretanto, defende a Teoria Estruturante do Direito uma proposta de análise da literalidade da lei como plano inicial (programa da norma), aplicada à realidade social escolhida ou criada pelo legislador (âmbito da norma), e que deve ser percebida pelo plano sensível do aplicador, mas também por dados da realidade e da ciência do Direito que o auxiliem na construção da normatividade.

Em relação ao âmbito da norma, aponta a Teoria Estruturante do Direito que esta é composta de elementos de concretização, que, por sua vez, são subdivididos em elementos dogmáticos; elementos de técnica de solução; elementos de teoria e elementos de política constitucional. É com relação aos primeiros, os elementos dogmáticos, que importa o estudo de teorias do Direito que auxiliem quando da concretização da norma de decisão.

Quando da aplicação da Teoria Estruturante do Direito a casos concretos, restaram ausentes, em algumas situações, conexões entre os elementos de concretização da norma de decisão e as consequências que porventura surjam de decisões que tratem de recursos escassos, nos quais trabalham agentes racionais. Nesse aspecto, surge a Análise Econômica do Direito (AED) como uma saída.

A relação entre Direito e Economia transformou-se, em meados do século XX, como referencial teórico instrumental para juristas pós-positivistas, e é utilizada, por vezes, como método de solução de controvérsias em que a norma jurídica não apresenta os resultados esperados, ou, ainda, não alcança uma solução efetiva. Sustentase, portanto, na noção de eficiência, como objetivo a ser alcançado quando da aplicação da norma.

Apesar de apresentar resultados expressivos quando de sua utilização, inclusive entre juristas e economistas 
brasileiros, sua exploração pode ser considerada incipiente, e submetida a uma série de rejeições teóricoinstrumentais, pautadas, por vezes, em preconceitos veiculados a uma tentativa de modificação da dogmática jurídica estabelecida.

Nesse sentido, questiona-se: existe a possibilidade de intersecção entre a Teoria Estruturante do Direito e a Análise Econômica do Direito, quando o aplicador da norma se deparar com uma situação de teoria jurídica aplicada ao elemento dogmático do âmbito da norma, mas ausente o seu elemento de concretização? A Análise Econômica do Direito pode ser utilizada como elemento dogmático do âmbito da norma na Teoria Estruturante do Direito?

Para responder a estes questionamentos, e utilizando-se de uma metodologia pautada por análise legal e doutrinária, objetiva-se apresentar a Teoria Estruturante do Direito, de Friedrich Müller, sob a ótica da Análise Econômica do Direito, enquanto elemento auxiliar de concretização da norma de decisão, na qual almejar-se-á demonstrar como a relação entre ambas as teorias pode servir como parâmetro de modificação da ordem dogmático-jurídica vigente.

Almeja-se concluir, portanto, que é possível, em razão dos elementos apresentados pela Teoria Estruturante do Direito e pela Análise Econômica do Direito, uma intersecção entre as duas teorias, e como a metodologia específica desta servirá como meio auxiliar de concretização da norma de decisão daquela.

Por oportuno, divide-se o trabalho em quatro partes distintas. A primeira, apresentará, de forma geral, a transmutação do movimento positivista ao movimento pós-positivista, como forma de embasamento para a Teoria Estruturante do Direito. A segunda, introduzirá a própria Teoria Estruturante do Direito, com especial ênfase ao trabalho de Friedrich Müller. A terceira, apresentará a Análise Econômica do Direito como método e disciplina, introduzindo seus conceitos gerais. A quarta, demonstrará, no âmbito da norma da Teoria Estruturante do Direito, a possível interseção com a Análise Econômica do Direito com atenção específica quanto a evolução da concepção de eficiência adotada pela AED, o que parece ser ponto de maior importância num conceito póspositivista.

\section{DO POSITIVISMO AO PÓS-POSITIVISMO}

A análise de uma evolução teórica do positivismo ao pós-positivismo é necessária para a compreensão dos temas principais do trabalho: a Teoria Estruturante do Direito e a Análise Econômica do Direito. Isso porque as duas são teorias que se baseiam em uma concepção pós-positivista, sendo que ainda são complementares em si.

Ressalte-se que, para melhor acepção do movimento positivista, faz-se necessário rememorar que sua origem se deu pela necessidade de segurança. É a origem do constitucionalismo e da legalidade, com a instituição 
do povo soberano de si mesmo, e a lei e a Constituição como suas garantias primordiais, que serviram de embasamento ideal ao surgimento do positivismo. Buscou-se, sobretudo, a proteção do povo contra a falta de limites do absolutismo monárquico (SALDANHA: 2000).

Pode-se afirmar que o movimento positivista jurídico que se instaurou no seio dos ordenamentos jurídicos modernos - entendidos estes aqueles que se delinearam de meados do século XIX até o final do século XX, se iniciou com Hans Kelsen, e foi posteriormente trabalhado por Herbert Lionel Adolphus Hart e, finalmente, por seu discípulo Joseph Raz.

Defende Hans Kelsen uma distinção entre Direito e Moral, em que os fundamentos do Direito devem ser buscados no próprio Direito. O sistema jurídico se legitimaria em si mesmo, e haverá, na maioria dos casos, uma norma de hierarquia superior a fundamentar a de hierarquia inferior, até se chegar a chamada norma hipotética fundamental (em sentido lógico-jurídico), a qual não deve se confundir com a Constituição (em sentido jurídicopositivo).

A verdade é que Hans Kelsen "não ignorou a carga valorativa que informa o fato jurídico, mas simplesmente ressaltou a necessidade de o fenômeno jurídico ser analisado como tal; independentemente de outras áreas do conhecimento" (FERNANDES; BICALHO: 2011; 108). Sua teoria, portanto, demonstrou-se efetiva, e em muito agradou os estudiosos da época.

Em sequência, Herbert Lionel Adolphus Hart trouxe à tona discussão acerca do positivismo enquanto questão de reconhecimento da norma pelo grupo que é por ela própria regulado (regra de reconhecimento). Traçou a distinção entre normas primárias (obrigacionais) e as normas secundárias (referentes às regras de reconhecimento), estas com o objetivo de unificar e fundamentar faticamente as normas primárias. A grande inovação de Herbert Lionel Adolphus Hart foi apresentar a regra de reconhecimento como um fato, e não mais como presunção lógica (como Hans Kelsen).

Foi Ronald Myles Dworkin quem apresentou síntese de quase todas (senão todas) as teorias positivistas em três tópicos: (a) o direito em uma comunidade "é um conjunto de regras especiais utilizado direta ou indiretamente pela comunidade com o propósito de determinar qual comportamento será punido ou coagido pelo poder público", aferidas quanto a sua validade (pedigree), (b) mas caso a regra não esteja prevista, impedido de não se manifestar, o julgador deve ir "além do direito na busca por algum tipo de padrão que o oriente na confecção de nova regra jurídica ou na complementação de uma regra jurídica existente”; e (c) "dizer que alguém tem uma 'obrigação jurídica' é dizer que seu caso se enquadra em uma regra jurídica válida", pois "na ausência de uma tal regra jurídica válida não existe obrigação jurídica" (DWORKIN: 2002; 27-28).

Esses pontos levaram ao questionamento dos limites da lei e da normatividade dos princípios, já que no 
positivismo jurídico os princípios possuíam apenas uma função norteadora, interpretativas, ou seja, uma condição subalterna da própria lei. (MELGARÉ, 2004).

Surge daí o retorno a uma relação entre o Direito e a moral, ou melhor, uma limitação valorativa do próprio Direito. No Brasil, o termo pós-positivismo foi incluído por Paulo Bonavides, e teve como expoentes de maior conhecimento nestas terras Robert Alexy e Ronald Myles Dworkin. Para tanto, reestrutura-se também a concepção de princípios, que passa a conter não apenas carga valorativa, mas também carga normativa.

Antes de seu falecimento, e após críticas ferrenhas de Ronald Myles Dworkin, Herbert Lionel Adolphus Hart passa a aceitar a possibilidade da norma de reconhecimento adotar, ainda que de forma mínima, aspecto moral com fins a resolver incorreções sistemáticas. Por fim, restou a Joseph Raz a defesa do positivismo jurídico (FERNANDES; BICALHO: 2011.; 109-110).

A discussão contemporânea evoluiu ao ponto de que não mais se discute em pensamento binário entre o positivismo e o jusnaturalismo. Assim, "o foco central da filosofia do direito não é mais a verificação de qual das teorias passadas deve prevalecer. O que se busca atualmente são as bases de uma nova teoria: o pós-positivismo" (FERNANDES; BICALHO: 2011; 114).

Ao teórico que interessa ao presente trabalho, Friedrich Müller, pós-positivista concretista responsável por desenvolver a Teoria Estruturante do Direito, já definiu sua própria teoria como pós-positivista, sendo certo que a evolução teórica acima apresentada se adéqua ao autor. Contudo, apesar de se autodenominar pós-positivista, não deixou de ser um crítico a uma teoria dos princípios e ao sopesamento, que considerou irracional (ALEXY: 2015).

\section{A METÓdicA ESTRUTURANTE E TEORIA ESTRUTURANTE DO DIREITO, SEGUNDO FRIEDRICH MÜLLER}

A Metódica Estruturante pode ser conceituada como um método de trabalho, componente de uma teoria superior, a qual pode ser denominada como Teoria Estruturante do Direito. Alia-se a metodologia com a prática em torno de um fenômeno de construção da normatividade jurídica, especialmente na seara do Direito Constitucional, mas que não se restringe apenas a ele (MÜLLER: 2007; 224).

O programa da norma, conforme a Metódica Estruturante, é criado por intermédio de todos os elementos determinantes da concretização das leis. Uma vez reconhecido um diploma legal como legítimo, deve-se aplicar ao tratamento do texto da norma desde metodologias tradicionais de interpretação, como a gramatical; genética; histórica e sistemática, até mesmo outras metodologias específicas, direcionadas à interpretação, como, por exemplo, as que envolvem as grandes áreas de estudo do Direito - Direito Penal; Direito Civil; História do Direito; Direito Comparado, entre outros (PALMER: 2015). 
Defende a Metódica Estruturante a distinção entre texto, tal como colocado por seu elaborador ou modificado por seus intérpretes no decorrer do tempo, e norma em si, mas não restrita apenas a estes. Enquanto concepção sistemática e pós-positivista, deve-se compreender o Direito como um ramo que deixou de se utilizar da interpretação reducionista da norma ao seu texto; do ordenamento jurídico a uma ficção artificial; da solução do caso a uma hipótese de incidência repleta de lógica, auferível por intermédio de silogismos, mas que desenvolveu, a partir da estrutura de normas jurídicas, a proposta de um modelo de teoria e práxis que abrange a dogmática, a metódica, a teoria do direito e não continua devendo a resposta ao positivismo (MÜLLER: 2000).

A norma surgirá somente após processo de concretização, com a construção da norma de decisão. Não é exatamente o que está prescrito no texto literal da lei. Pode ir além, vez que analisada de forma estruturada e dialética também com a realidade (âmbito da norma). Não há que se confundir texto positivo com norma. Não será a qualidade de ter sido lavrada e publicada que denota a normatividade de um texto. Essa só surge na elaboração da norma de decisão, e com a ajuda de elementos auxiliares (MÜLLER, 2005). Portanto, é a passagem da norma jurídica (potencial de decisão) à norma de decisão de um caso jurídico concreto que lhe confere real normatividade (CANOTILHO, 2003).

A norma não se limita apenas ao texto, mas também ao contexto social em que foi inserido. É proposta a divisão da norma em dois elementos: o programa da norma (texto literal) e o âmbito da norma (realidade social escolhida ou criada pelo legislador a ser normatizada).

O âmbito da norma é considerado um fator constitutivo da normatividade, vez que há intensa interrelação entre as dimensões fática - com o âmbito normativo e jurídica - com o programa normativo, vez que designa uma qualidade de porosidade recíproca, e cujo produto será, a princípio, uma norma jurídica geral e abstrata, mas que, por sua vez, pode ser analisada mediante uma perspectiva valorizada pelo seu próprio programa (STAFFEN; CALLETI: 2016; 78).

A concretização vai além da interpretação da norma. A interpretação é apenas um elemento do método da concretização. É um processo estruturado com vários elementos a serem destacados, passando-se por todos eles, ou apenas por alguns. A concretização da norma - especialmente da norma constitucional- não acontece somente pelos tribunais juízes, mas por todos os atores envolvidos no plano social.

Dessa forma, "também os atingidos que participam da vida política e da vida da constituição desempenham funções efetivas de concretização da constituição de uma abrangência praticamente não superestimável" (MÜLLER: 2005/35-36).

O processo de concretização é estruturado através de elementos metodológicos strictu sensu para o programa da norma (cânones da interpretação estabelecidos por Friedrich Carl von Savigny e princípios de 
interpretação comum daquele ramo do direito - seja constitucional, seja infraconstitucional), e elementos do âmbito da norma. São estes os elementos dogmáticos, de teoria, de técnicas de solução e de política do direito e política constitucional. Os primeiros três elementos estão referidos a norma - o terceiro apenas em parte - sendo que os últimos três seriam apenas auxiliares ao processo de concretização (MÜLLER: 2005; 37-38).

Deve-se ressaltar, entretanto, que "o programa da norma é elaborado por meio de todas as determinantes da concretização das leis, reconhecidas como legítimas, como tratamento do texto da norma desde as já mencionadas interpretação gramatical, genética, histórica e sistemática, até as figuras interpretativas específicas das grandes áreas do direito penal, do direito civil, da história do direito e do direito comparado" (MÜLLER: 2007; 224).

Parte-se do texto literal da lei (programa da norma) em ordem estrutural de complementaridade entre os elementos de concretização. Portanto, alcança-se a norma de decisão, ou seja, a norma concretizada ao caso jurídico. A metódica estruturante se baseia não em um abandono dos métodos tradicionais de interpretação, mas no reconhecimento que o pós-positivismo requer a interpretação da norma apenas como passo necessário à sua concretização, que se dará completa somente após a análise dialética de elementos adicionais trazidos pela teoria ao trabalho da metódica (MAGALHÃES: 2005).

Evidencia-se que a Teoria Estruturante do Direito defende a atuação da Metódica Estruturante na construção da norma de decisão, com respaldo pós-positivista, e pautada em um método escalonado de elementos de concretização. Parte-se do texto para a realidade, e da realidade para as limitações apresentadas pelo texto em um processo dialético de interseção de elementos concretizadores pré-definidos (elementos metodológicos strictu sensue elementos do âmbito da norma).

Entre estes elementos, os do âmbito da norma são divididos em dogmáticos, de teoria do Direito, de técnicas de solução e de política do direito e política constitucional. Entre estes, os elementos dogmáticos interessam a presente pesquisa, vez que são neles que se pode interagir com as bases da Análise Econômica do Direito.

O elemento de dogmática, assim com todos os outros elementos vinculados ao âmbito da norma, possui tão somente o caráter de convencimento, não sendo vinculantes ao intérprete-aplicador da norma. Trata-se do estudo das decisões dos tribunais (jurisprudência) e da doutrina nacional e internacional. São modos de trabalho que não raras vezes influenciam na decisão de casos jurídicos. Importa, ainda, que a prática das normas de decisão resultará em enunciados futuros de caráter dogmático, o que demonstra seu lugar como elemento auxiliar do âmbito da norma (MÜLLER: 2005; 83).

O caráter de dogmática jurídica requer que o elemento seja aplicado não por questões de racionalidade 
jurídica, em termos políticos ou de política jurídica, ou seja, não ser subjetivo. Mas sim, ser mentalmente recapitulável, portanto, criticável. (MÜLLER: 2005; 84-85).

\section{A ANÁLISE ECONÔMICA DO DIREITO ENQUANTO POSSIBILIDADE: A CIÊNCIA JURÍDICA DIANTE A EFICIÊNCIA E A ESCASSEZ DE RECURSOS}

A maior preocupação dos juseconomistas é tentar definir: a) quais as consequências jurídicas de um determinado ordenamento jurídico; e, b) qual a regra jurídica que deve ser adotada em caso concreto (GICO JR: 2010; 18-19). Pode-se afirmar que a primeira indagação independe da segunda, mas esta, por outro lado, não ocorre, tendo em vista que o ordenamento jurídico é determinante da regra jurídica que será aplicada a um específico caso concreto (RODRIGUES: 2007; 34).

O ordenamento jurídico é composto por um sistema de incentivos. Assim, analisar os efeitos de diferentes espécies desses sistemas é uma das principais ocupações dos economistas. O primeiro tipo de questões mencionado corresponde à análise positiva do Direito, e está relacionada a um critério de verdade. Já o segundo remete à análise normativa, a qual está relacionada a um critério de valor.

Sendo assim, como realizar a aplicação da Análise Econômica do Direito? De saída, se impõe uma distinção entre AED positiva (o que é) e AED normativa (o que deve ser); essa diferenciação traz uma série de indagações que serão devidamente respondidas, antes de se adentrar o estudo da metodologia da AED propriamente dita (SALAMA: 2008; 5-7).

\section{Análise Econômica (positiva e normativa) do Direito: diferenciação necessária}

A Análise Econômica do Direito tem aspectos positivos (descritivos) e normativos. Por um lado, tenta explicar e prever o comportamento, tanto dos elaboradores de leis, por exemplo, como das pessoas reguladas por elas, ou seja, tanto pelos elaboradores do Direito como pelos indivíduos que são regulados por ele (POSNER: 1998; 4). A AED tenta, ainda, aprimorar o Direito, apontando-lhe circunstâncias nas quais as leis propostas ou as já existentes podem gerar consequências indesejadas ou, ainda, não intencionais.

Faz-se necessária a distinção entre positivo e normativo para explicar o mundo como ele é e tratar de transformá-lo para melhor, mais eficiente. Essa mesma diferenciação é necessária para se compreender como funciona a AED (POSNER: 1998; 4-8). Enquanto ciência autônoma, a Análise Econômica do Direito reconhece, tal como tantas outras ciências, a distinção entre "o que é" (positivo) e "o que deve ser" (normativo), sendo que a primeira proposição se correlaciona com um critério de verdade e a segunda com um critério de valoração 
(GICO JR:: 2010; 19).

Nesse contexto, pode-se verificar uma diferença de estudos; de um lado, o mundo dos fatos que podem ser investigados e averiguados por métodos científicos, cujos resultados são passíveis de uma verificação (análise positiva); e, de outro, um estudo de valores, que não são passíveis de investigação empírica (não lhes cabendo prova ou falsificação) e, portanto, não são científicos (análise normativa). Quando da análise econômica de um homicídio, pode-se partir de dois pontos de vista distintos: primeiramente, quando um juiz, por exemplo, investiga se A matou B, ele está realizando uma análise positiva (investiga um fato específico) (SALAMA: 2008; 9). Entretanto, quando o legislador questiona se naquelas circunstâncias aquela conduta deveria ser punida, realiza uma análise normativa (investiga uma valoração), ainda que os fatos sejam relevantes para essa decisão. Tal proposição é conhecida como a Guilhotina de Hume, em alusão à obra "Tratado sobre a Natureza Humana", de David Hume, um dos precursores do movimento.

A teoria central da Guilhotina de Hume consiste na impossibilidade de deduzir-se o dever-se do ser, ou seja, que proposições puramente factuais só possam levar a ou implicar outras proposições puramente factuais, e jamais em julgamentos valorativos. Pode-se concluir, pelas ideias de David Hume, que fatos não levam a proposições éticas e vice-versa, o que pressupõe uma clara distinção entre o mundo dos fatos e dos valores. Quando realizada a aplicação da Guilhotina de Hume à ciência jurídica, diversos problemas podem ser encontrados. O contexto cultural, a ideologia, a visão política e a história do pesquisador podem influenciar de várias formas o objeto de estudo e a metodologia aplicada, tornando a distinção entre positiva e normativa em um complexo debate (GICO JR: 2010; 20). A AED positiva auxilia a compreensão da norma jurídica de fato, qual a sua racionalidade, e, também, quais as diferentes consequências prováveis decorrentes da adoção de uma ou outra regra. Com isso, consiste numa abordagem eminentemente descritiva e explicativa, com resultados preditivos.

Nesse contexto, tendo como finalidade compreender se a proposta de um instrumento legal atinge seu objetivo normativamente pré-determinado, é necessário se fazer uso de uma ferramenta analítica descritiva. $\mathrm{O}$ argumento central da AED positiva é o de que a microeconomia pode oferecer métodos consistentes para desenvolver essa análise de meios e fins. Dessa maneira, quando um pesquisador de AED utiliza seu instrumental para realizar uma análise positiva, pratica a ciência econômica aplicada ao direito. Nesse momento, o juseconomista positivista não é capaz de oferecer quaisquer sugestões de políticas públicas ou de determinada decisão que deverá ser tomada. No máximo, o pesquisador conseguirá identificar as possíveis alternativas normativas, se serão textuais, com técnicas hermenêuticas, ou poderá investigar as prováveis consequências de cada uma das opções, aplicando-se AED, e comparar a eficiência de cada solução possível, com uma análise custobenefício (GICO JR:: 2010; 20). Com isso, os fundamentos teóricos mais úteis para análise podem ser 
encontrados na Teoria dos Custos de Transação, de Ronald H. Coase; na Teoria da Escolha Racional; e, finalmente, na Nova Economia Institucional.

Por sua vez, a AED normativa está direcionada a um critério de escolha. Entre diversas possibilidades, auxilia na adoção da opção mais eficiente, ou seja, induzindo a opção pelo melhor arranjo institucional dado um valor previamente definido. Estabelecidas diversas maneiras de se alcançar determinada finalidade, permite que se conheça qual a opção menos custosa, de forma a indicar aquela mais eficiente. Registre-se, entretanto, que é uma maneira de se encarar a $\mathrm{AED}$ normativa, uma vez que, conforme ressaltado anteriormente, a $\mathrm{AED}$ não se propõe a dar respostas definitivas para dilemas normativos (SALAMA: 2008; 10-11). Até porque a AED tem como uma de suas principais características o fato de não ser doutrinária.

A Economia, ou qualquer outra linha de pensamento, não pode compelir determinado julgamento moral. A Ciência Econômica é completamente neutralizada, neste parâmetro, objetivando, no debate moral e políticojurídico, preocupar-se com consequências e implicações que os indivíduos que ignoram o método econômico geralmente não percebem. Entretanto, o que os indivíduos decidem a partir do momento em que tomam conhecimento de tais consequências corresponde somente à sua liberdade de manifestação. A função da abordagem econômica seria a de tão somente visualizar as consequências de determinadas instituições, ainda que não sejam adversas ou custosas (POSNER: 1998; 2).

A AED é uma teoria sobre comportamentos, e não um parâmetro de avaliação de condutas. Não se deve confundir um método de análise realizado pela disciplina com um julgamento de valor. O principal objetivo da AED não é igualar a eficiência à justiça, mas tentar compreender como a justiça pode se beneficiar do exame de prós e contras dos custos e benefícios de uma análise econômica (GICO JR: 2010; 20).

O método econômico baseia-se em alguns postulados que, uma vez adquiridos pelo juseconomista, facilitam a análise econômica dos fatos jurídicos (GICO JR.; 2010: 22-23), quais sejam:

i) Escassez: os recursos da sociedade são escassos, ocasionando, com isso, problemas econômicos, tendo em vista a insaciável vontade humana. Não sendo escassos os recursos, não haveria problemas econômicos. E o mesmo ocorre com o Direito. Se os recursos não fossem escassos, não haveria conflitos, e, sem conflitos, não haveria necessidade do Direito, uma vez que todos cooperariam por sua própria vontade. A escassez dos bens impõe à sociedade a escolha entre alternativas possíveis e excludentes.

ii) Custo de Oportunidade (custos de transação): todas as escolhas pressupõem um custo, que consistem exatamente na segunda alocação factível mais interessante para o recurso, mas que foi preterida. Com isso, uma vez que determinado indivíduo, por exemplo, decida comprar caças para fortalecer a Aeronáutica, abdicará de outra alocação que esses recursos poderiam ter. 
iii) Racionalidade Maximizadora: com escolhas a serem realizadas, os agentes econômicos ponderam os custos e os benefícios de cada alternativa. Dadas as circunstâncias e condições do caso concreto, os agentes adotam as condições que mais lhes agradam, ou seja, que mais lhes trazem bem-estar. Atuam, portanto, de maneira racional maximizadora.

iv) Resposta a Incentivos: dependendo da estrutura de incentivos, mesmo que determinado agente econômico realize suas escolhas, pode ser que tenha de adotar outra conduta, e realiza outra escolha. Sabe-se que as pessoas respondem a incentivos. E o Direito, da mesma maneira, também atua mediante incentivos, tal como, por exemplo, o que ocorre na política de incentivos fiscais ou, ainda, com a diminuição ou majoração de penas. Por responderem a incentivos, as pessoas geram uma reação na Ciência Jurídica, tornando-a útil e formadora de regras jurídicas buscando a segurança e a paz social.

v) Mercado: com as pessoas respondendo a incentivos, o comportamento dos agentes pode ser colocado em um contexto hierárquico ou mercadológico. No primeiro caso, a interação entre os agentes é regida por regras de comando, como ocorre nas relações de emprego, na relação familiar ou na hierarquia militar. Entretanto, no segundo caso, quando a conduta é resultante da livre interação entre os agentes, ocorre o mercado.

vi) Equilíbrio: quando a interação social dos agentes se dá no âmbito do mercado, o comportamento racional maximizador levará os agentes a realizar trocas, ou seja, barganhas (não necessariamente pecuniárias), até que os custos associados a cada troca se igualem aos benefícios auferidos (os custos de transação seriam eliminados), momento a partir do qual não ocorreriam mais trocas. Encontra-se o equilíbrio, que consiste no conceito técnico utilizado para explicar qual será o resultado provável de uma alteração na estrutura de incentivos dos agentes. Ainda no conceito de equilíbrio, existe o que se denomina como sendo "Pareto-eficiente", ou seja, pode ocorrer que não exista nenhuma outra alocação de certo recurso de tal forma que determinado indivíduo não consiga melhorar a sua situação sem piorar a dos demais. Estes equilíbrios constituem o ótimo de Pareto. Por conseguinte, pessoas maximizam, e os mercados equilibram.

Muitas ferramentas econômicas podem ser úteis para a Análise Econômica do Direito, mas, para facilitar o entendimento sobre sua aplicação, tratar-se-á da temática central do trabalho a partir de alguns exemplos, com a aplicação de algumas ferramentas econômicas, a serem explicadas no decorrer da argumentação.

3.2 As ferramentas utilizadas na realização de uma Análise Econômica do Direito.

A maioria dos estudantes e pesquisadores de AED define que, apesar das diversas escolas, as ferramentas utilizadas para se realizar uma interação entre Direito e Economia são as mesmas, alterando-se, somente, o método pelo qual são aplicadas. Mantém-se o mesmo objetivo, qual seja, o de aplicar à ciência jurídica ferramentas 
econômicas visando maior eficiência (PARISI; KLICK; 2003: 432).

Nesse contexto, estão, dentre as primeiras características de uma AED: a) a rejeição do entendimento de estudantes e pesquisadores de Direito tradicionalistas, que o consideram um ramo autônomo e alheio às realidades sociais, ou seja, uma ciência completamente isolada das demais; b) a utilização das ideias e métodos de outras disciplinas na análise da realidade jurídica, principalmente a Economia e a Sociologia; e, finalmente, c) a reação ao convencionalismo ou tradicionalismo, uma concepção dominante até a década de 1960, que tinha como tese fundamental o antirreducionismo à filosofia, à política e à economia, bem como uma rejeição ao raciocínio abstrato e a hostilidade em relação ao conhecimento e à ciência exata (ALVAREZ; 2006: 58).

Tradicionalmente, os integrantes da academia jurídica iniciam as suas análises partindo do pressuposto de que o Direito é composto por normas e seu objeto prioritário de pesquisa é identificar o conteúdo e o alcance dessas normas. É por isso que um jurista tradicionalista, preocupado com a preservação do patrimônio históricocultural, poderia discutir se "cultura" integra o conjunto de significados associados à expressão "meio ambiente", e, se a resposta for positiva, se prédios históricos gozam da mesma proteção e limitações impostas pelas leis ambientais para áreas verdes (GICO JR.; 2010: 21).

O estudioso da AED, por sua vez, tem como principal característica considerar o direito enquanto um conjunto de regras que estabelecem custos e benefícios para os agentes que determinam os seus comportamentos em função de tais incentivos.

Seguindo-se o mesmo exemplo de proteção ao patrimônio histórico-cultural, um juseconomista faria os seguintes questionamentos: a) como os agentes efetivamente têm se comportado diante da regra atual (diagnóstico), que não incide sobre o patrimônio cultural; e, também, b) como uma mudança da regra jurídica alteraria essa estrutura de incentivos (seja essa mudança realizada por alteração legislativa, por modificação de entendimento jurisprudencial, entre outros), na tentativa de se provar como eles passariam a se comportar (realizando a prognose). Assim, respondendo a essas perguntas (análise positiva), o juseconomista aventurar-se-ia numa análise normativa.

Se tivesse de ser definido o objeto da Economia, provavelmente seria constituído como sendo todos os fenômenos sociais que envolvem escolhas sobre a utilização de recursos escassos. Com isso, inevitavelmente, muitos destes fenômenos são também estudados por outras disciplinas sociais, como o Direito, proporcionando uma análise precisa com a utilização de ferramentas econômicas comuns (e, também, outras específicas, se existirem) (RODRIGUES; 2007: 12).

O que distingue a Economia do Direito, ou de outras ciências sociais, portanto, não é o seu objeto, que, conforme mencionado, podem coincidir, mas o método utilizado para se conseguir seus objetivos. O método da 
Economia consistiria, sucintamente, nos três seguintes princípios: a) o primeiro é o de que os agentes econômicos, ou seja, as pessoas que fazem escolhas, atuam de forma racional; b) o segundo é o de que comportamentos coletivos se deduzem das escolhas individuais; e, finalmente, c) o terceiro princípio é o de que a eficiência é, no plano normativo, o critério fundamental para se avaliar a ação humana (RODRIGUES; 2007: 12).

Entretanto, por mais simples que possa ser a ideia de se aplicar ao Direito ferramentas eminentemente econômicas, não é uma tarefa possível exclusivamente ao estudo tradicional, uma vez que, para ser capaz de compreender como se comporta o agente e tentar prever suas reações e mudanças em sua estrutura de incentivos, é necessário que se tenha à disposição uma teoria sobre o comportamento humano, inexistente na Ciência Jurídica, mas existente na Economia (GICO JR.; 2010: 22). E é o que fazem os juseconomistas, emprestando a teoria sobre o comportamento humano ao Direito, e proporcionando a aplicação da AED.

\section{$\underline{\text { A Teoria da Escolha Racional e Individualismo Metodológico }}$}

Para explicar o comportamento dos agentes e realizar a análise positiva da ação humana, o juseconomista adota como unidade básica de análise a escolha individual de cada agente ou de pequenos grupos envolvidos no problema, postura denominada como individualismo metodológico (GICO JR.; 2010:24).

Para se explicarem comportamentos coletivos, deve-se, antes de tudo, analisar-se o comportamento individual ou de um pequeno grupo que compõe aquela coletividade. Ao analisar-se, por exemplo, o Poder Judiciário, deve-se primeiro compreender o incentivo concedido aos membros que o compõem (cada magistrado ou um pequeno grupo deles), a dinâmica entre juízes e desembargadores e destes com os ministros, e assim sucessivamente.

Para se compreender o conceito promovido pelos estudos da AED, faz-se necessário que, anteriormente, sejam conhecidos quais os postulados da microeconomia adotados pelo movimento, ou seja, as premissas do individualismo metodológico e das escolhas racionais, tal como relacionado anteriormente (COELHO; 2007: 17-18).

O individualismo metodológico consiste em uma tentativa de derivar todo o comportamento econômico, partindo de uma ação humana coletiva em busca da maximização de suas vantagens, estando sujeitos, por exemplo, aos obstáculos da tecnologia e das alocações. (BLAUG; 1980: 315).

Dessa forma, todo e qualquer fenômeno social coletivo consiste no resultado combinado de escolhas individuais. A partir da disciplina da AED, os efeitos de um determinado ordenamento jurídico sobre o bem-estar coletivo podem, e devem ser analisados como sendo resultante da soma das respostas individuais a tal ordenamento, ou seja, uma resposta coletiva aos incentivos concedidos. 
$\mathrm{O}$ individualismo metodológico consiste apenas em um instrumento analítico, em que estão ausentes implicações éticas no sentido de representar uma postura pela qual os interesses individuais devem ser maximizados, ou que os agentes devem se comportar de determinada maneira. A AED, afinal, é formada por uma teoria sobre comportamentos, e não um parâmetro de avaliação de condutas (GICO JR;; 2010: 24). Conforme ressaltado anteriormente, na AED encontram-se ausentes influências a alterar valores. Por sua vez, a teoria da escolha racional, para o juseconomista, consiste num conceito técnico que pode ser expresso mediante três formas distintas (GICO JR; 2010: 26):

a) Preferências: o agente econômico racional tem gostos específicos, podendo ser denominados como preferências. Não se avalia por que determinado indivíduo tem essas preferências, tendo em vista que a Economia utiliza teorias sobre os meios empregados pelas pessoas para alcançarem os seus fins, e não sobre os fins que elas buscam, ou seja, analisa-se o comportamento, e não a sua motivação.

b) Utilidade: cada indivíduo atribui uma utilidade a cada escolha possível, sendo capaz de ordenar as escolhas de acordo com as utilidades que lhe proveem. Tendo duas opções, por exemplo, o agente econômico escolherá aquela que lhe for mais útil, ou seja, condiciona-se a uma racionalidade maximizadora de utilidade.

c) Análise Marginal: os agentes econômicos decidem racionalmente com base nos custos de desenvolver certa atividade; interessa-lhes em que proporção a unidade adicional da atividade desenvolvida trouxe mais benefício do que custou desenvolvê-la. Assim, a teoria da racionalidade será aplicável quando continuar desenvolvendo uma atividade útil para o agente econômico.

Seguindo-se a Teoria da Escolha Racional, faz-se um paralelo entre preços e normas jurídicas a fim de se compreender como estas últimas influenciam o comportamento dos agentes. Para se reduzir o nível de infrações às regras jurídicas ou a prática de quaisquer ilícitos, em caráter geral, deve-se ajustar o preço da realização de tais atividades. Em tese, qualquer atividade ilegal, por exemplo, de início seria desestimulada pela majoração da penalidade correspondente.

\section{Modelagem e Reducionismo}

Outra ferramenta relevante para análise dos fatos jurídicos consiste na utilização de modelos para explicar o comportamento humano, uma vez que a ciência busca compreender e explicar o mundo. O modelo científico funcionaria como um mapa, podendo ser mais ou menos realista dependendo das necessidades do usuário (GICO JR; 2010:25).

Como o mundo real apresenta uma infinidade de características e grande complexidade, os juseconomistas elaboram modelos teóricos de problemas que desejam investigar, e nos quais apenas variáveis 
consideradas relevantes são consideradas, ou seja, funciona como um estudo direcionado. Assim procede o juseconomista na medida em que objetiva simplificar o problema para obter novas perspectivas.

Ressalte-se que determinados problemas, mesmo com variáveis restritas, poderão ganhar o acréscimo de outras, se assim forem necessárias, dependendo do caso concreto.

\section{Eficiência}

A Análise Econômica do Direito, partindo do princípio de que são utilizados os pressupostos de microeconomia para alcançar seus objetivos encontra-se relacionado com o conceito de eficiência, da mesma forma que é estudada e compreendido pelos economistas (COELHO; 2007: 18).

Os economistas encontram várias maneiras de definir o que significa eficiência e que qualquer processo pode ser classificado como eficiente quando ocorrer qualquer uma de duas condições: a) não ser possível produzir a mesma quantidade de um determinado bem, utilizando uma combinação menos custosa de insumos; ou, ainda, b) não ser possível produzir uma quantidade maior de um determinado produto usando a mesma combinação de insumos (COOTER; ULEN; 2010: 17).

Podem ser citados outros conceitos de eficiência, tal como o que defende Vilfredo Pareto, em sua teoria da eficiência alocativa. Para ele, a eficiência seria o ponto de equilíbrio no qual seria impossível melhorar determinada situação de um indivíduo sem prejudicar ou piorar a de outro. Com isso, a configuração ideal de eficiência implica em um ótimo social, uma vez que, estando cada um relativamente satisfeito, com o bem nas mãos daquele que mais o valoriza, a eficiência se aproximaria da maior possível (PARISI; 2004: 4-12).

A utilização das conclusões de Pareto apresenta certas limitações, na medida em que, quando aplicadas a temáticas específicas de Direito, exigem a aplicação de critérios de eficiência diferenciados. O critério de Pareto exige que qualquer indivíduo que almeje uma melhora na sua situação, deverá arcar com a compensação dos indivíduos que tiveram uma perda, objetivando manter o equilíbrio da relação existente entre eles (COELHO; 2007:22).

Enquanto considerada uma eficiência potencial, a teoria de Pareto admite mudanças em que existam vencedores e perdedores, mas, em contrapartida, requer que os ganhos dos primeiros sejam maiores que as perdas dos segundos. Ressalte-se, porém, que o conceito de eficiência potencial apenas implica uma compensação que possa ser realizada, não a impondo como uma obrigatoriedade; o considera, mais uma vez, o equilíbrio da relação.

Satisfeita essa condição, os vencedores poderiam, em teoria, compensar os perdedores e ainda assim obter uma melhora para si. Trata-se de análise de custo-benefício, cujo princípio consiste na vantagem de se empreender um projeto sempre que seus benefícios excederem seus custos, e esse tipo de análise deverá levar em consideração 
tanto os custos e benefícios privados quanto os sociais (COELHO; 2007: 23).

\section{$\underline{\text { Teoria dos Jogos }}$}

A Teoria dos Jogos consiste em um conjunto de instrumentos com linguagem própria para descrever e tentar prever o comportamento estratégico do agente econômico. A teoria modela e estrutura o comportamento do indivíduo, de forma a torná-lo aplicável a uma grande variedade de situações, independentemente do número de jogadores. Envolve a teoria, ainda, além de questões econômicas, qualquer outra motivação que envolva a tomada de decisões interdependentes por vários agentes.

$\mathrm{Na}$ interação entre dois ou mais indivíduos, e levando-se em consideração que suas ações se baseiam naquilo que esperam ou desejam que os outros façam, existe o comportamento estratégico, podendo-se tratar a sua relação como um "jogo". Com isso, a Teoria dos Jogos auxilia a compreender e prever as estratégias racionais desses indivíduos, a partir da definição do que são as regras do jogo (PINHEIRO; SADDI; 2005: 157).

A Teoria dos Jogos se propõe estudar as ações humanas em sociedade, ou seja, em interdependência. Tanto as ações que se realizam, como os resultados que se obtém, dependem das ações dos demais indivíduos. Por esse motivo, se associa a Teoria dos Jogos às estratégias, tratando de determinar quais são as ações que os “jogadores" seguirão para assegurar os melhores resultados possíveis (KRAUSE; 2006: 54).

Os elementos da Teoria dos Jogos podem ser elencados como: a) jogadores, os indivíduos que tomam as decisões tratando de obter o melhor resultado possível, ou seja, maximizar a sua utilidade; b) ação, uma das opções que os jogadores têm disponíveis para alcançar seu objetivo; um conjunto de ações são todas as ações possíveis e uma ordem de jogo definirá em que momento estas ações estarão disponíveis; c) informação, que é o conhecimento, em um determinado momento, dos valores e das distintas possibilidades, ou seja, os valores distintos que o jogador considera possíveis; d) estratégia, que consiste no conjunto de ações a tomar em cada momento do jogo, tendo em vista a informação disponível; e) recompensa, que é a utilidade que recebem os jogadores ao completar o jogo; f) resultado, isto é, as conclusões que o modelador, aquele que concede as regras do jogo, obtém, uma vez que se tenha jogado; e, finalmente, g) equilíbrio, que consiste no perfil de estratégias integrado para realizar as melhores ações para cada um dos jogadores (KRAUSE; 2006: 55).

A problemática central da Teoria dos Jogos é a assimetria de informações que se tenta compreender e mitigar. Elaborar as regras que deem os incentivos corretos para que os indivíduos se comportem de maneira a trazer benefícios para toda a sociedade seria uma tarefa simples, caso fossem disputadas as informações perfeitas, quando da aplicação da Teoria dos Jogos ao Direito. Entretanto, surgem complicações quando informações relevantes sobre o comportamento dos indivíduos não são conhecidas, ou ao menos não o são para algumas 
partes ou para as cortes.

Para ilustrar a aplicação da Teoria dos Jogos, cite-se o denominado "dilema do prisioneiro". Neste caso, dois indivíduos são acusados de praticar um grave crime, mas foram capturados pela polícia. Contudo, todas as evidências contra eles são circunstanciais, de forma que, se levados a julgamento e se declarassem inocentes, ambos sofreriam uma pena branda (no máximo dois anos de prisão, por exemplo). Assim, quando aprisionados pelas autoridades, os suspeitos são levados a interrogatório separadamente, de forma que os interrogadores tentarão colocá-los um contra o outro, a fim de obterem uma delação premiada, ou seja, que um denuncie o outro.

A partir das informações concedidas pela polícia, pode-se formar um conjunto de ações possível e as regras do jogo. Caso qualquer dos suspeitos confesse o crime, acusando também seu companheiro e este, por sua vez, continue em silêncio, o primeiro receberá como recompensa pela sua colaboração uma redução da pena, sendo condenado a somente seis meses de prisão (1/4) enquanto o segundo sofrerá uma pena maior, equivalente a 8 (oito) anos. Se ambos os suspeitos confessarem, receberão a mesma pena: 5 (cinco) anos cada um.

Nessas circunstâncias, o que cada um deveria fazer: confessar ou permanecer em silêncio? Com os dados fornecidos é possível formular matriz, em uma situação como a seguinte (KRAUSE; 2006: 75):

\begin{tabular}{|l|l|}
\hline $5-5$ & $1 / 4-8$ \\
\hline $8-1 / 4$ & $2-2$ \\
\hline
\end{tabular}

A matriz acima reúne graficamente todos os possíveis desdobramentos do jogo, tendo em vista as regras concedidas pela polícia. Se ambos os suspeitos confessarem, a pena será de cinco anos para cada um. Se o Suspeito A confessar e o Suspeito B permanecer em silêncio, o primeiro receberá a pena de oito anos de prisão enquanto o segundo receberá apenas seis meses, e vice-versa. Se ambos permanecerem em silêncio, a pena dos dois será idêntica, equivalente a dois anos.

Ao tomar-se em conta que os suspeitos se encontram separados, e assim não tiveram oportunidade de combinar suas ações, um não tem informações de como o outro irá proceder. Eles poderão somente avaliar, individualmente, qual será a melhor atitude a tomar considerando todas as circunstâncias, e, com isso, tentar maximizar a sua utilidade. Caso o Suspeito B decida confessar, o Suspeito A recebe a pena de oito anos se silenciasse, ou a pena de cinco anos se confessasse. Claramente, a melhor escolha seria a segunda, em razão de maior utilidade para o indivíduo que participa do jogo.

Entretanto, e se o Suspeito B decidir manter-se em silêncio? Neste caso, se o Suspeito A também permanecer em silêncio, ambos receberão a pena de dois anos de prisão. Mas, se ele confessar, sua pena será de 
apenas seis meses. Sendo assim, novamente, sua melhor opção é confessar o crime.

Portanto, qualquer que seja a atitude do Suspeito B, a melhor estratégia para o Suspeito A será confessar. Nos termos próprios da Teoria dos Jogos, esse tipo de situação denomina-se estratégia dominante, o que significa que a estratégia ótima para um determinado jogador será sempre a mesma, independentemente das ações do outro jogador.

Entretanto, como o Suspeito B se encontra em situação idêntica à do Sujeito A, sua estratégia dominante também será confessar. Dessa forma, ambos receberão a pena de 5 anos. Mas observe-se que este não é um resultado Pareto eficiente. Ambos poderiam desfrutar de uma situação melhor caso permanecessem em silêncio, recebendo a pena de dois anos de prisão. Contudo, isso somente seria possível se os indivíduos tivessem antecipado a possibilidade de ocorrência dessa situação, combinando informações.

Desse raciocínio pode-se deduzir outra importante ferramenta em Teoria dos Jogos, o de jogos repetitivos. Supondo que o dilema do prisioneiro ocorra não somente uma vez, mas diversas vezes, com os mesmos jogadores; se ambos se encontrarem na mesma situação, com as mesmas regras, reiteradas vezes, é possível que os jogadores desenvolvam um comportamento cooperativo, buscando, para tornar isso viável, estabelecer uma reputação de que são confiáveis.

No caso de jogos repetitivos, faz-se necessário saber se o jogo será repetido em uma quantidade prédeterminada de vezes ou se será repetido indefinidamente. Uma vez estabelecida a diferença, e supondo que o dilema do prisioneiro será repetido exatamente dez vezes, a estratégia ótima para cada jogador deverá ser pensada ao longo de todos os jogos, e não apenas em cada rodada individualmente. Após a primeira rodada, os suspeitos teriam a percepção de que, para ambos, a melhor estratégia, cada vez que se repetisse o jogo, seria permanecerem em silêncio, exceto na décima rodada.

Por ser a última rodada, o Suspeito A, por exemplo, teria um forte incentivo para confessar, tendo em vista que sua pena será reduzida para seis meses, ou seja, um quarto da pena, considerando que o Suspeito B mantenha a estratégia de permanecer em silêncio. Entretanto, se o Suspeito B tiver a mesma ideia, e, para não ter que receber a pena de oito anos no último jogo, sua melhor estratégia também será confessar. A conclusão lógica seria a de que, na décima rodada, ambos confessariam e receberiam a pena de cinco anos.

Com isso, para evitar essa situação, o jogo 9 passaria a ser considerado o jogo final. Mas a mesma lógica do jogo 10 se aplicará para o jogo 9, regredindo para o jogo 8 e para cada rodada anterior, sucessivamente. A estratégia de confessar acabará, de qualquer forma, se tornando a estratégia dominante, caso o jogo seja repetido com em um número fixo de vezes.

Ressalte-se que se não houver perspectiva de fim na repetição dos jogos, a cooperação poderá ser induzida, 
de forma que, se a melhor estratégia para os jogadores em uma rodada qualquer for cooperarem um com o outro, não haverá, inicialmente, incentivos para não manterem essa estratégia nos jogos subsequentes. A cooperação, portanto, poderá ser mantida indefinidamente.

A Teoria dos Jogos apresenta um nível de complexidade e aplicabilidade muito maior do que o previsto no dilema do prisioneiro com dois participantes; diversos trabalhos desenvolvem proposições, tal como o de Martín Krause (2006, p. 57), a sinalização, o equilíbrio de Nash, a teoria da barganha e outras que seriam passíveis de aplicação à Ciência Jurídica.

\section{A Nova Economia Institucional}

A Teoria da Nova Economia Institucional pode ser considerada como o ramo mais proveitoso da AED contemporânea (SALAMA; 2008: 15). Pode-se dividir em, pelo menos, três postulados principais:

a) o reconhecimento de que a Economia não tem existência independente dos acontecimentos históricos e sociais; uma vez que o mundo real está repleto de contextos culturais, sociais, políticos e jurídicos, a aplicação da Ciência Econômica torna-se cada vez mais custosa e, em alguns momentos, é inviável aplicar mudanças exageradas;

b) o reconhecimento de que não há como se compreender o Direito quando isolado de uma análise evolucionista e central da diversidade e complexidade dos processos de mudança social, ou seja, pressupõe-se que a Ciência Jurídica concederá abertura para outras disciplinas além da Economia, e concederá a possibilidade de aplicação, por exemplo, da Teoria da Escolha Racional e a Teoria dos Jogos para compreender-se a complexidade dos processos de ação e decisão coletiva; $\mathrm{e}$

c) a compreensão do mundo real como elemento fundamental, tal qual se apresenta, conduzindo ao estudo das práticas efetivamente observadas e do Direito como de fato é aplicado, levando-se em consideração a racionalidade limitada, a incerteza e os custos de transação.

O termo "institucional" é adotado como reflexo de uma realidade em que a decisão de quem efetivamente decide será considerada a decisão válida, ou seja, aquela de quem realmente decidirá, na prática, quais os seus efeitos. Tomadores de decisão alternativos não são indivíduos ou, ainda, um pequeno número de indivíduos, mas compõem um complexo processo de decisão, tal como o processo político, de mercado ou judicial, em que a interação de múltiplos participantes modela a sua performance (KOMESAR; 1994: 16).

Por intermédio dessa definição das instituições, é possível afirmar-se que a escolha institucional não se 
limita a uma única análise institucional, mas, de forma comparativa, a um processo de decisão que exige uma comparação das alternativas. Portanto, escolher a melhor instituição, em um determinado cenário, é o principal objetivo da análise institucional comparativa (COSTA; 2016:365).

A análise baseia-se na mensuração da participação, e detém, como regra central da abordagem e da participação, que as mudanças legais não ocorrerão sem um impulso das partes interessadas. A escolha institucional é fundamental para descrever o panorama real, e é ainda mais relevante em um contexto em que as instituições não funcionam adequadamente, e carecem de legitimidade ou governabilidade, como no Brasil (RIBEIRO; 2011:267).

A Teoria da Nova Economia Institucional, portanto, defende o desenvolvimento generalizado da Economia em outros domínios das ciências sociais, e verificando que algumas instituições como partidos políticos, associações, organizações privadas, dentre outras, são estudadas a partir de uma abordagem científica unificada.

Mediante a adoção de postulados fundamentais como o individualismo metodológico e a busca pela utilização eficiente de recursos escassos, a AED se encaixaria nos objetivos da Nova Economia Institucional, ou Neoinstitucionalismo, que, por sua vez, analisa as atividades estatais e a sociedade de acordo com a eficiência alocativa. A teoria aborda as instituições, como elas surgem, quais os seus propósitos, como são alteradas, reformadas e outras.

As instituições constituem restrições elaboradas pelo homem que moldam as interações humanas, determinando a estrutura das relações econômicas, políticas e sociais, tendo como objetivo reduzir as incertezas e impor a ordem nas relações entre os agentes econômicos (NORTH; 1990: 361).

Existem dois tipos de instituições, quais sejam: as formais e as informais. Seriam exemplos das formais as normas jurídicas, e ainda outras garantias dessas normas, como os princípios jurídicos, os costumes, as tradições, as regras de conduta, entre outras. Seriam informais, por sua vez, aquelas instituições difusas encontradas diariamente no comportamento social dos agentes econômicos, e geralmente incorporadas a ele mediante um processo muitas vezes não identificável. E são as instituições, aliadas com as leis econômicas e as tecnologias empregadas, que definem o conjunto de possibilidades de escolha dos agentes econômicos, determinando os custos de transação, de produção, entre outros. Ressalta-se, ainda, que a informação constitui elemento essencial, na medida em que determinará os custos de transação (NORTH: 1994; 361).

A Nova Economia Institucional deu grande importância ao processo de alteração institucional, destacando, para tanto, que no processo formal os atores econômicos são reconhecíveis, e no informal isso não ocorre com facilidade (SZTAJN; AGUIRRE; 2005: 228-229). E a formação de cada instituição representaria o 
motivo pelos quais as instituições informais são mais resistentes que as formais.

A possibilidade de um eventual equilíbrio institucional é dificilmente alcançada, em razão das instituições serem alteradas constantemente, porque existem em razão da incerteza e para tentar amenizá-la (ou corrigi-la). Portanto, o único tipo de eficiência que poderiam alcançar seria a adaptativa (SZTAJN; AGUIRRE; 2005: 230).

Haveria, portanto, uma dicotomia entre os benefícios obtidos com a estabilidade das instituições, tendo em vista que auxiliam na redução da incerteza, e os obtidos pelos processos de mudança, provocados pela busca da eficiência adaptativa.

A estabilidade e a mudança são dois elementos extremos, que podem estar em conflito no momento em que se busca a estrutura institucional que procure a maximização do desempenho econômico. Por sua vez, o excesso de estabilidade pode gerar perda de oportunidades e a consequente estagnação, enquanto que o excesso de mudança pode trazer incerteza e a consequente paralisia do sistema.

\section{PONTOS DE INTERSECÇÃO DA ANÁLISE ECONÔMICA DO DIREITO COM A TEORIA ESTRUTURANTE DO DIREITO}

A interdisciplinaridade do Direito com outras ciências talvez seja um dos mais instigantes temas dos últimos anos. Longe de ser pacífica, é relação que atrai críticos e apaixonados, bem como apresenta novos problemas e novas soluções. É a prova que muitas vezes um entendimento meramente jurídico não se mostra suficiente para a resolução dos diversos problemas da vida real.

A ciência jurídica, ao tratar de fatos que condizem com a vida, é considerada como um ramo científico que prega à interdisciplinaridade. Nesse sentido, o Direito interage com outros campos científicos, denominadas ciências afins, tais como a Filosofia, a Sociologia e a Economia. O entendimento do Direito como uma ciência independente não pode mais subsistir, e, para tanto, sua interação será, por vezes, necessária (REALE: 2007; 3132).

Entre uma das relações citadas, encontra-se a entre o Direito - ciência que objetiva regular a conduta humana em sociedade - e a Economia - ciência que busca a forma mais eficiente de utilizar recursos escassos em uma sociedade.

Ao todo exposto, tem-se a AED como tentativa de superação do positivismo jurídico através de estudo de âmbito consequencialista. Como não mais se busca focar no mero silogismo normativo, mas em atuações voltas à aspectos valorativos de justiça, afirma-se que a Análise Econômica do Direito encontra no pós-positivismo terreno fértil para seu desenvolvimento (GICO JR: 2010; 15).

Não há que se confundirem resultados com consequências para argumentos de análise consequencialista. Resultado é o estado de coisas que existem antes das consequências. Uma análise consequencialista leva em 
consideração a relação entre resultados e consequências com implicações lógicas e em caráter hipotético. São as consequências jurídicas, a justificar decisões em razões finalistas e em razões de correção (ATIENZA: 2000).

A titulo de interação com a Teoria Estruturante do Direito, necessário compreender a distinção clássica já apresentada pela doutrina da Análise Econômica do Direito em análise positiva - descrevendo o que se é - e análise normativa - descrevendo como se deve ser. Parte da ideia de que há diferenças entre o mundo dos fatos, que pode ser investigado e averiguado por métodos científicos, cujos resultados são passíveis de falsificação (análise positiva), e o mundo dos valores, que não é passível de investigação empírica, de prova ou de falsificação. Portanto, não cientifico (análise normativa) (GICO JR.: 2010; 15).

A Análise Econômica do Direito, em análise normativa, é comumente utilizada para se prever ou compreender o comportamento dos agentes frente a alterações legislativas ou jurisprudencias. Trata-se de instrumental que capacita o estudioso de meios necessários a tomar decisões mais racionais e próximas dos seus objetivos iniciais (TABAK: 2015).

Ao adentrar no tema do trabalho, a intersecção da Teoria Estruturante do Direito com a Análise Econômica do Direito, tem-se o elemento dogmático do âmbito da norma como aquele que se utilize da dogmática jurídica (doutrina e jurisprudência) sendo destinado ao convencimento do julgador no processo de concretização da norma. Neste, o instrumental teórico da Análise Econômica do Direito é de extrema valia. Principalmente por apresentar uma teoria do comportamento humano, que tanto falta ao Direito (ALVAREZ: 2006).

Sobre o tema, Jolss, Sustein e Thaler, publicaram paper em volta do comportamento humano na Análise Econômica do Direito chamado "A behavioral approach to law and economics", em crítica ao pensamento econômico-racionalista (JOLSS; SUSTEIN; THALER: 2008).

Em um processo estruturado de concretização da norma de decisão, importa que a análise normativa da Análise Econômica do Direito, acima citada, apontando os impactos e possíveis resultados da aplicação de uma norma, pode servir de convencimento para aquele que seria o melhor resultado, então, a melhornorma de decisão a ser concretizada. Ou seja, a AED auxiliaria a se concretizar a norma de decisão com maior qualidade (eficiência) e respeito ao ordenamento jurídico que a lhe sustentaria. Daí necessário compreender a noção maior do conceito de eficiência para a Análise Econômica do Direito, a qual já se discutiu em com maiores detalhes tópico anterior, e que agora será lembrada somente para fins de congruência com o tema da relação com a Teoria Estruturante do Direito.

Em economia a noção de melhor é intimamente ligada ao conceito de eficiência. O conceito de eficiência, por sua vez, sempre foi atrelado àquele de eficiência econômica. Ou seja, a melhor alocação de recursos finitos 
(escassos). Para a AED, o critério de eficiência comumente aceito é aquele introduzido por Richard A. Posner em Economic Analyis of Law (1973), e posteriormente em outros trabalhos, especialmente The Economics of Justice (1981). O critério adotado é da eficiência como "maximização de riqueza". Há uma veia consequencialista nesta teoria, visto que o conceito de riqueza adotado por Posner (2007) era o de valor econômico, ou seja, o que se está disposto a pagar ou a receber por um bem ou serviço.

O posicionamento restou alterado por Richard A. Posner, em seu Problemas de Filosofia do Direito (2007), quando passa a considerar a maximização de riqueza apenas mais um dos valores de uma teoria de justiça própria. O que se pode considerar como espécie de pragmatismo próprio. (SALAMA, 2010).

Sob inúmeras críticas, a visão de Richard A. Posner foi alterada. Contemporaneamente, diante das diversas acepções de justiça, a eficiência pode ser considerada uma delas, mas não só. Pactos eficientes em sentido econômico não serão necessariamente justos (ou legais), como que deveriam ser (POSNER: 2007). Tal conceito de eficiência encontra-se em consonância com o raciocínio pós-positivista, e com a Teoria Estruturante do Direito.

Esta concepção de eficiência encontra respaldo

Não se apresentam outros entraves à Análise Econômica do Direito como dogmática jurídica, pronta a ser aplicada como elemento dogmático da Teoria Estruturante do Direito. Seu âmbito normativo possibilita previsões sobre o comportamento humano e efetividade da norma de decisão. Tem-se assim a expressão da parcela da realidade que a Teoria Estruturante do Direito tanto se orgulha de defender.

\section{Conclusão}

Após análise da Teoria Estruturante do Direito, da metódica jurídica de Friedrich Müller e dos conceitos básicos a Análise Econômica do Direito, conclui-se que esta é referencial teórico valioso que serve como base dogmática a ser utilizada como elemento de dogmática do âmbito da norma.

Para tanto, iniciou-se a pesquisa através de uma rápida evolução do positivismo ao pós-positivismo, onde se concluiu que a Teoria Estruturante do Direito, uma das teorias jurídicas que se desenvolveu devido ao póspositivismo, é bem recebida e aplicada no Brasil.

Em seguida, analisou-se conceitos básicos da Teoria Estruturante do Direito e da sua metódica jurídica, percebendo-a ser teoria que defende a concretização da norma de decisão através de interseção dialética do texto da lei (programa da norma) com o recorte da realidade criado ou escolhido pelo Direito (âmbito da norma).

Empós, introduziu-se a Análise Econômica do Direito, com ênfase em sua analise normativa e no conceito de eficiência não apenas como maximização de riqueza, mas como um critério de uma teoria de justiça, onde a 
riqueza é apenas um dos valores perseguidos. Notou-se que estes entendimentos permitem que se perceba a AED como teoria dogmática de interesse a Teoria Estruturante do Direito, devido a seus pontos de intersecção.

Pelo fim da pesquisa, conclui-se que a Análise Econômica do Direito é referencial teórico valioso para à Teoria Estruturante do Direito, em específico como elemento dogmático do âmbito da norma. Auxilia, portanto, na concretização da norma de decisão, devido ao seu caráter consequencialista que reforça a validade do argumento apresentado pela AED e fornece instrumental previsível e eficiente.

\title{
ECONOMIC ANALYSIS OF LAW AS A CONCRETIZING ELEMENT IN THE LAW STRUCTURING THEORY
}

\begin{abstract}
The present research aimed to demonstrate the possibility of intersection between the Structuring Theory of Law and the Economic Analysis of Law (EAL). In a qualitative way, it was verified through a logical-deductive methodology based on a bibliographical revision, that from the doctrinal evolution of the positivist to the postpositivist movement, the use of the Economic Analysis of the Right became a fundamental tool for the concretization of the Structuring Theory of Law, with, even, complementation of its characteristics around an efficient Law in cases whose resources are scarce and limited. It was concluded that the EAL can be applied as a dogmatic element of the scope of the Theory of Structuring Law, as an auxiliary that enables the implementation of the best decision rule, especially for the possibility of forecasting the normative analysis.
\end{abstract}

Keywords: Law Standards; Structuring Theory of Law; Economic Analysis of Law; Best decision rule; Positivism.

\section{REFERENCIAS}

ALEXY, Robert. Teoria dos Direitos Fundamentais. 2 ed. São Paulo: Malheiros, 2015.

ALVAREZ, Alejandro Bugallo. Análise econômica do direito: contribuições e desmistificações. Direito, Estado e Sociedade. v.9, n. 29, pp.49-68, jul-dez, 2006.

ATIENZA, Manuel. As Razões do Direito: teorias da argumentação jurídica. São Paulo: Landy, 2000.

BLAUG, Mark. The Metodology of Economics: or how economists explain. Cambridge: Cambridrge University Press, 1980.

BOBBIO, Norberto. Da Estrutura à Função: novos estudos de teoria do Direito. São Paulo: Manole, 2007.

BONAVIDES, Paulo. Curso de Direito Constitucional. 24. ed. São Paulo: Malheiros, 2009. 
CANOTILHO, José Joaquim Gomes. Direito constitucional e teoria da Constituição. 7. ed. Coimbra: Almedina, 2003.

COASE, Ronald. The Problem of Social Cost. Journal of Law and Economics, n. 3, p. 1-23, 1961.

COELHO, Cristiane de Oliveira. A Análise Econômica do Direito enquanto ciência: uma explicação de seu êxito sob a perspectiva da História do Pensamento Econômico. In: Latin American and Caribbean Law and Economics Association (ALACDE) Annual Papers, Berkeley Program in Law and Economics, UC Berkeley, 2007. Disponível em: <http://escholarship.org/uc/item/47q8s2nd> Acesso em: 26 jan. 2017.

COOTER, Robert; ULEN, Thomas. Direito \& Economia. Trad. Luis Marcos Sander e Francisco Araújo da costa, 5. ed. Porto Alegre: Bookman, 2010.

COSTA, Rafael de Oliveira. Metodologia e Epistemologia da Análise Econômica do Direito. In: Economic Analysis of Law Review, v. 7, n. 2, p. 362-386, jul./dez. 2016.

DWORKIN, Ronald Myles. Levando os direitos a sério. Tradução e notas Nelson Boeira. São Paulo: Martins Fontes, 2002.

FERNANDES, Ricardo Vieira de Carvalho; Guilherme Pereira Dolabella Bicalho. Do positivismo ao póspositivismo jurídico: o atual paradigma jusfilosófico constitucional. Revista de Informação Legislativa, Brasília, Senado Federal, a.48, n. 189, jan-mar, 2011, pp. 105-131.

GODOY, Arnaldo Sampaio de Moraes. Direito e Economia: introdução ao movimento law and economics. Revista da Presidência, Brasília, Presidência da República. v.7, pp. 01-10, nº 73, jun/jul, 2005. Disponível em: < https://revistajuridica.presidencia.gov.br/index.php/saj/article/view/437/431> Acesso em: 01/11/2016

GICO JR, Ivo. Metodologia e Epistemologia da Análise Econômica do Direito. Economic Analysis of Law Review, Brasília, v.1, n.1, p.7-33, jan-jun, 2010.

Introdução ao Direito e Economia. In: TIMM, Luciano Benetti (Coord.). Direito e Economia no Brasil. São Paulo: Atlas, 2012.

KOMESAR, Neil K. Imperfect Alternatives: choosing institutions in Law, Economics, and Public Policy. Chicago: The University of Chicago Press, 1994.

KRAUSE, Martín. Análisis Económico del Derecho: aplicación a fallos judiciales. Buenos Aires: La Ley, 2006.

JOLLS, Christine; SUNSTEIN, Cass R.; THALER, Richard. A behavioral approach to law and economics. Stanford Law Review, Califórnia, v. 50, mai, 1998, pp. 1451-1550.

MAGALHÃES, Marco Túlio Reis. Hermenêutica constitucional: comparação das teorias de Konrad Hesse e Friederich Müller. Revista da Presidência, Brasília, Presidência da República, v.7, no. 75, out./nov., 2005. Disponível na Internet: <https://revistajuridica.presidencia.gov.br/index.php/saj/article/view/480/473> Acesso em: 01/11/2016.

MELGARÉ, Plínio. Princípios, regras e tese do direitos. Revista de Informação Legislativa, Brasília, Senado Federal, a.41, n. 162, jul-set, 2004, pp. 97-112. 
MÜLLER, Friedrich. Positivismo. Tradução de Peter Naumann e revisão de Paulo Bonavides. In: Boletim dos Procuradores da República. Ano III, n. 29, setembro, 2000

Métodos de Trabalho de Direito Constitucional. Tradução de Peter Naumann. $3^{a}$ ed. Rio de Janeiro: Renovar, 2005.

O novo paradigma do direito: introdução à teoria e metódica estruturantes. São Paulo: Editora Revista dos Tribunais, 2007.

NORTH, Douglass C. Institutions, institutional change and economic performance. New York: Cambridge University Press: 1990.

PALMER, Richard E. Hermenêutica. Lisboa: Edições 70, 2015.

PARISI, Francesco. Positive, Normativa and Functional Schools in Law and Economics. In: European Journal of Law and Economics, v. 18, n. 3, dez. 2004.

PARISI, Francesco; KLICK, Jonathan. Functional Law and Economics: the search for value-neutral principles of lawmaking. In: Special Workshop on Law and Economics and Legal Scholarship, 21 st IVR World Congress, Lund, Suécia, 2003.

PINHEIRO, Armando Castelar; SADDI, Jairo. Direito, Economia e Mercados. Rio de Janeiro: Elsevier, 2005.

POSNER, Richard A. El análisis económico del derecho. 2 ed. México: FCE, 2007. Values and Consequences: an introduction to economic analysis of law. In: University of Chicago Law School, Program in Law and Economics Working Paper 53. 1998.

REALE, Miguel. Lições Preliminares de Direito: Adaptado ao Novo Código Civil. 27. ed. São Paulo: Saraiva, 2007

RODRIGUES, Vasco. Análise Económica do Direito: uma introdução. Coimbra: Almedina, 2007.

SADDI, Jairo; PINHEIRO, Armando Castelar. Direito, Economia e Mercados. São Paulo: Campus, 2005

SALDANHA, Nelson. Formação da teoria constitucional. Rio de Janeiro: Renovar, 2000.

SALAMA, Bruno Meyerhof. A História do Declínio e Queda do Eficientismo na Obra de Richard Posner. In: LIMA, Maria Lúcia L. M. Pádua (Coord.). Trinta Anos de Brasil: Diálogos entre Direito e Economia. São Paulo: Saraiva, 2010.

O que é “Direito e Economia?". In: TIMM, Luciano Benetti (Org.). Direito \& Economia. 2 ed. (rev. e atual.). Porto Alegre: Livraria do Advogado, 2008.

STAFFEN, Marcio Ricardo; CALLETTI, Leandro. O conflito entre princípios na teoria estruturante do direito de Friederich Müller. Revista de Direito Brasileira, v. 13, p. 74-87, 2016.

SZTAJN, Rachel; AGUIRRE, Basília. Mudanças Institucionais. In: ZYLBERSZTAJN, Decio; SZTAJN, Rachel. Direito \& Economia: análise econômica do direito e ds organizações. Rio de Janeiro: Elsevier, 2005. 
TABAK, Benjamim Miranda. Análise Econômica do Direito: proposições legislativas e políticas públicas. Revista de Informação Legislativa, Brasília, Senado Federal, a.52, n. 205, jan-mar, 2015, pp.321-345.

Trabalho enviado em 08 de outubro de 2017.

Aceito em 18 de janeiro de 2018. 